\title{
Effect of Different Eggshell Powder on Appearance of Eggshell Maki-e
}

\author{
Yutaro Shimode $^{1 *}$, Chieko Narita ${ }^{2}$, Atsushi Endo ${ }^{2}$, Kazushi Yamada $^{2}$ \\ ${ }^{1}$ Department of Traditional Arts and Crafts, Kyoto College of Arts and Crafts, Kyoto, Japan; ${ }^{2}$ Department of Advanced Fibro-Sci- \\ ence, Kyoto Institute of Technology, Kyoto, Japan. \\ Email: *shimode-yutaro@xa2.so-net.ne.jp
}

Received November $17^{\text {th }}, 2012$; revised December $25^{\text {th }}, 2012$; accepted January $21^{\text {st }}, 2013$

\begin{abstract}
The Maki-e technique with eggshell powder is one of techniques of Japanese traditional Urushi (Japanese lacquer) crafts. However, this technique is relatively new in the history of Maki-e, and there are no prior researches in terms of materials, structure, and properties. In this research, therefore we have aimed to evaluate the relationship between the eggshell powder sizes, dispersion, and color shade in Maki-e with eggshell powder. The difference between hen's and quail's eggshell characteristics and the effect of their powder particle size on appearance of eggshell Maki-e were discussed on the basis of the results of the particle size, circularity, particle number, and RGB value. As a result, it was found that the occupancy of the eggshell powder on the surface depends on not particle number but the particle size, whereas the whiteness of both eggshell powders depends on the particle size.
\end{abstract}

Keywords: Urushi (Japanese Lacquer); Maki-e; Eggshell Powder; Traditional Crafts

\section{Introduction}

As the worldwide current state of Urushi (Japanese lacquer or lacquer) research as a material, polymer science and chemical analysis is main research field [1-9]. Archaeology and cultural assets field of Urushi are also studied positively [10-13]. However, there are few research reports which are focused on the painting technique of Japanese Urushi as a craft.

Urushi crafts have been conducted as one of the traditional crafts in not only Japan but also Southeast Asia such as China and South Korea, etc. [14], however Maki-e technique, i.e. the picture drawn by Urushi with gold and/or silver powder, is a distinctive technique in Japan.

Urushi crafts decorated with Maki-e had been expanded worldwide through East India Company in the Middle Ages, and these crafts had attracted European nobles like Maria Theresia and Marie Antoinette [15].

Powder which is used for Maki-e is usually gold and/or silver powder. However, the dry blending powder, that is called "Kanshitsu powder", which is made by mixing the Urushi and the pigments, is used to express the color shade. It is difficult to express the white color by mixing the Urushi and the white pigment, because the Urushi is the sap obtained from Rhus verniciflua and it is not white but amber color originally. Therefore, hen's

${ }^{*}$ Corresponding author. and quail's eggshell are generally used for expressing the white as a one of the Urushi crafts techniques.

Japan has an exceedingly long history in the use of Urushi for about 9000 years, whereas the eggshell technique is relatively new because it has been used for Urushi crafts since 300 or 400 years ago [16]. Nevertheless a lot of great works were produced by many craftspeople including Gonroku Matsuda and Naoji Terai [17] who were Japanese living national treasure.

In a general creative process of Maki-e with eggshell powder, the eggshell is put on the surface painted with the Urushi. In addition to this method, it is frequently used as powder by changing the particles size of the eggshell in recent years as shown in Figure 1. This method is called "eggshell powder Maki-e" and can make it possible to express the various white degrees and impressions by changing the particle size. However, the existing studies which are focused on Maki-e are almost about the research with using gold powder. There are no prior researches and data related to the eggshell powder Maki-e. Therefore, it is very important to investigate the relationship between the powder size and the difference in vision in order to contribute to the succession of the technique of eggshell Maki-e. In this research, we demonstrate the relationship between the different kinds of eggshell, i.e. hen's and quail's eggshell characteristics and the powder size on appearance of eggshell Maki-e. 


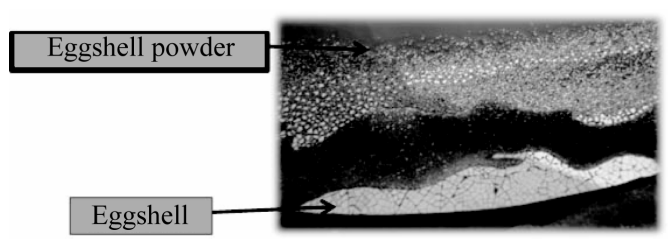

Figure 1. Photo image of the difference in eggshell powder and eggshell.

The effects are discussed on the basis of the results of particle analysis, circularity, and occupancy on the surface of the eggshell Maki-e substrate.

\section{Experimental}

\subsection{Materials}

Hen's and quail's eggshells were used as material for this research. These materials were very normal and Urushi craftspeople generally use them. After removing inner thin skins of eggshell, those were crashed by a druggist's mortar. The eggshell powder was riddled into 6 grades by using 7 kinds of sieves dedicated to Urushi crafts. Samples were 6 kinds of a mesh count filtered powders (mono-count) and 3 kinds of the mixed powders with two types of mesh cunt filtered powder (di-counts) as shown in Table 1.
The making process and the externals photographs of the samples are shown in Figures 2 and 3, respectively. The each sample has the different filling rate of the powder.

\subsection{Sample Preparation Methods Specifications}

Pictures of samples were taken by Digital microscope (VHX-900, KEYENCE Japan, valid pixels; $1600 \times 1200$ ). These pictures were converted to $1000 \times 1000$ pixel data by Photoshop CS5 (Adobe Systems Incorporated). Igor Pro (6.22A, HULINKS Inc.) was used as analysis software.

\subsubsection{Particle Size and Circularity, Particle Number and Occupancy}

Measurement points are shown in Figure 4. Each sample was divided into 25 pieces equally, and measuring points were 4 rows except no powder left row. Two points were extracted from each measurement range. Average particle number and occupancy rate of 10 points per one line were calculated. Occupancy rate was calculated by dividing occupancy area of eggshell powder by total area. A pixel equals $1.79 \mu \mathrm{m}$ in this experiment. Calculated value was recalculated into $\mu \mathrm{m}$ because it was pixel value.

Table 1. Six mono-counts and three di-counts which were used in this experiment.

\begin{tabular}{|c|c|c|c|c|c|c|c|}
\hline \multirow[b]{2}{*}{ Mono-count } & \multicolumn{6}{|c|}{ Count } & \multirow{2}{*}{$\frac{\text { Total }}{6}$} \\
\hline & $800-100$ & $100-120$ & $120-150$ & $150-180$ & $180-200$ & $200-250$ & \\
\hline
\end{tabular}

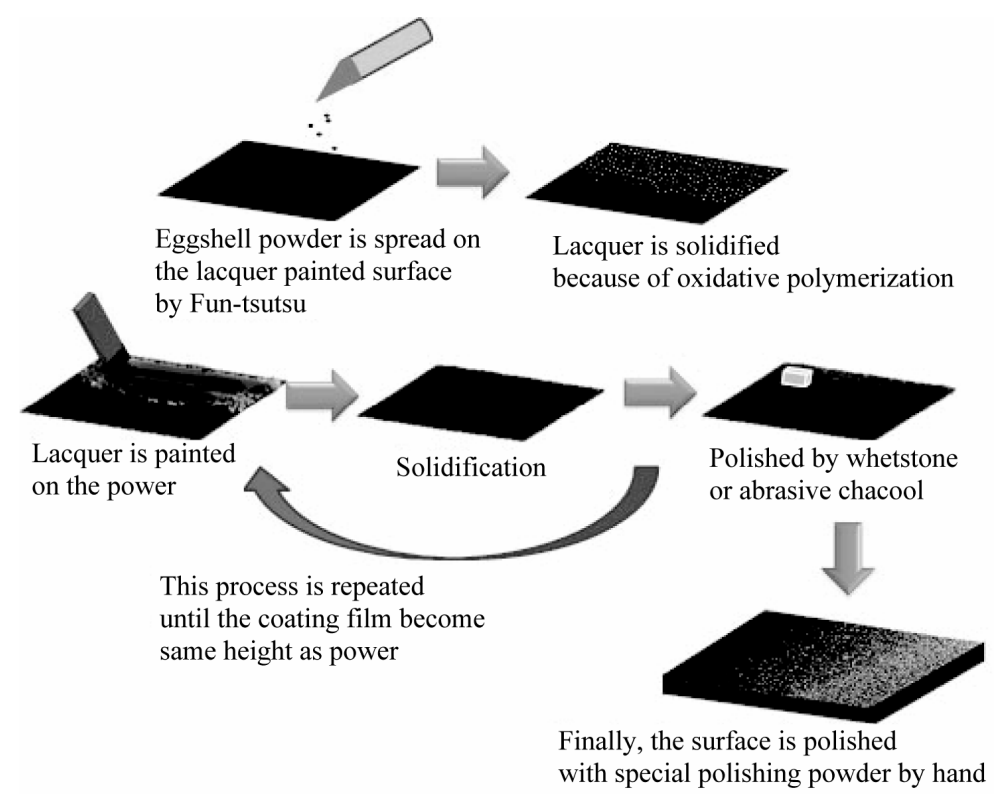

Figure 2. Schematic illustration of the process of preparing the sample. 


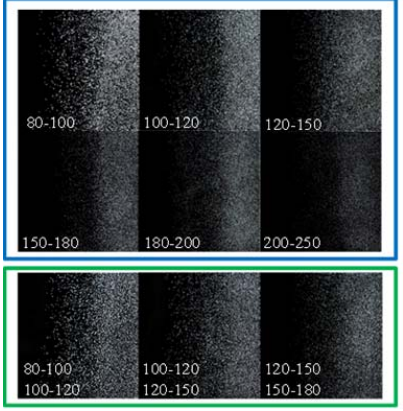

(a)

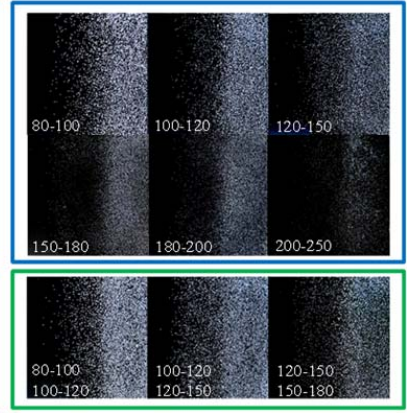

(b)
Figure 3. Picture of samples prepared by different counts; (a) Quail's eggshell powder; (b) Hen's eggshell powder.

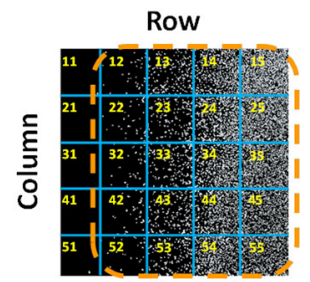

Figure 4. Schematic illustration of measuring points for each sample.

\subsubsection{Cross-Sectional Observation}

Cross-sectional observation was done to observe the particle distance and the sinking condition of powder.

\subsubsection{RGB Value and Value, Full Width Half Maximum}

RGB value and value were measured to compare both powder colors. In addition, full width half maximum was measured to confirm if whiteness of powder depend on the particle size.

\section{Result and Discussion}

\subsection{Particle Size and Circularity, Particle Number and Occupancy}

Firstly, the particle size before and after polishing was measured in order to evaluate the effect of polishing for the eggshell powder. Both eggs' average area of a particle before and after polishing the surface is shown in Figure 5.

The polygonal line in this figure shows the decrease ratio of the average area of both eggshells. The average particle size of these powers was decreased with increasing the number of the mesh counts filter, i.e. the particle size was proportional to the magnitude of the mesh holed size. The decrease ratio of the particles area in the quail's egg was increased with increasing the number of the mesh counts filter, whereas in the case of Hen's egg, the same tendency was not indicated. Therefore, it is considered that the kind of eggshell is attributed to the diffe-

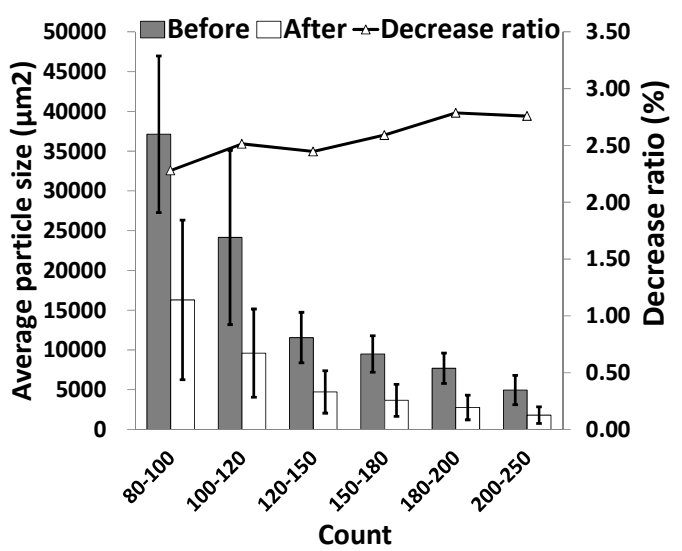

(a)

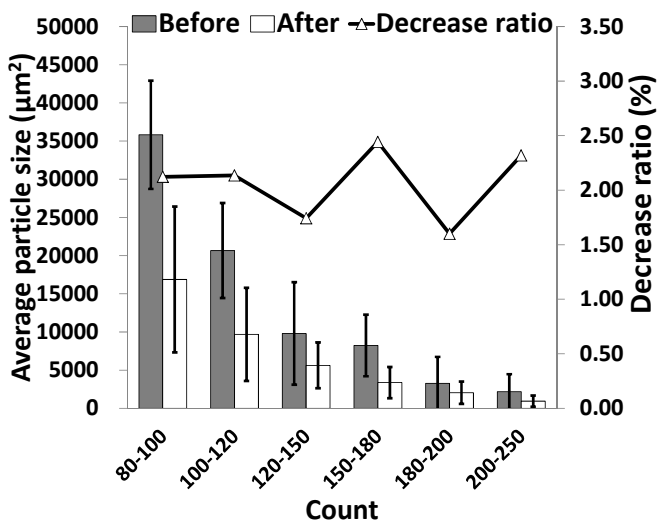

(b)

Figure 5. Average particle size and the decrease ratio of a particle before and after processing; (a) Quail's eggshell powder; (b) Hen's eggshell powder.

rence of the structure and/or materials of eggshell.

Figure 6 shows the circularity of these eggshells before and after polishing. As shown in this figure, the circularity of all measured values was decreased after polishing on the surface of substrate. The decrease ratio after processing of Hen's egg was bigger than that of quail's egg. Since the eggshell was crashed with the agate mortar, the outer perimeter of eggshell fragments became the rugged shape. As a result, the circularity of these fragments is low. However, after polishing, the circularity of all measured value was also decreased, the softness of the eggshell results in the decrease of the circularity.

The number of particle and the occupancy per unit area after processing are shown in Figure 7. In the case of both mono- and di-counts, the number of particles was increased with increasing the number of the mesh counts filter, and the occupancy was decreased with increasing the number of the mesh counts filter. In addition, the dispersion of particle number was decreased with increasing the number of the mesh counts filter, i.e. it is 


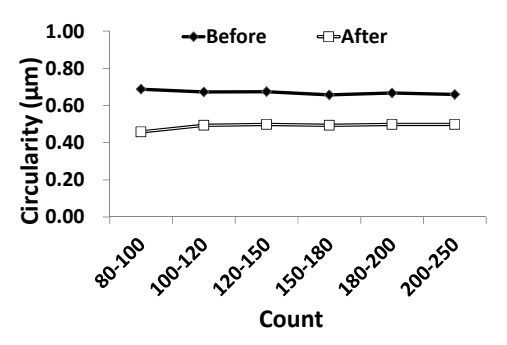

(a)

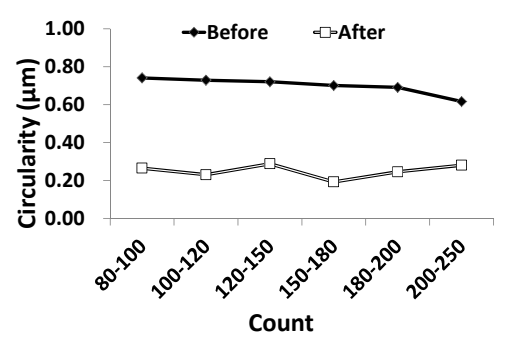

(b)

Figure 6.Circularity before and after processing; (a) Quail's eggshell powder; (b) Hen's eggshell powder.

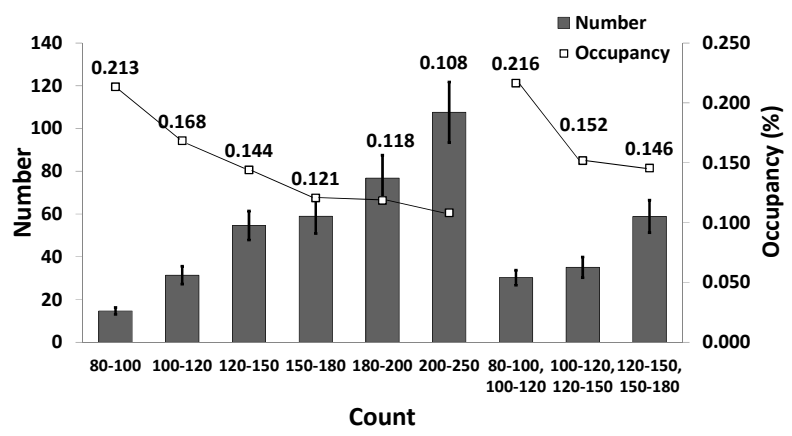

(a)

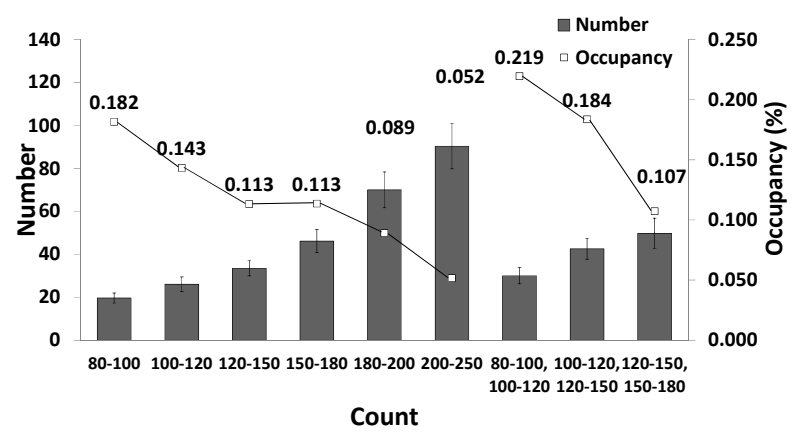

(b)

Figure 7. Particle number and occupancy per unit area after processing; (a) Quail's eggshell powder, (b) Hen's eggshell powder.

indicated that the dispersibility was improved with decreasing the hole size of mesh count filter. On the other hand, the occupancy of the eggshell treated with dicounts indicated the high value as compared with that of mono-count. It could be due to that the small particles filled up the gap between the large particles.

\subsection{Cross-Sectional Observation}

Figure 8 shows the typical high magnification photo images of specimens for the different mesh cunts filter, i.e. 80 - 100 and 200 - 250. In general, it is noted that the interparticle distance is decreased with decreasing the particle size, whereas the occupancy of the particles on the surface is increased with increasing the number of particles. However, in this experiment, it seems that the tendency of decrease is not observed for these specimens. Therefore, it is important to define a reason for the decrease of occupancy as the number of particles was increasing.

Figure 9 shows the typical cross-sectional picture of specimens for the different mesh cunts filter, i.e. 80 - 100, 150 - 180, and 200 - 250. In this figure, A and B are corresponding to the part of eggshell powder and Urushi coating film, respectively. From the 80 - 100 count pictures, it is clear that the diameter of big particle size powder is equal to or bigger than the Urushi coating film thickness. Thereby, it is considered that there is not likely accompanied by the loss of powders on the surface and the dipping of powders into the film. On the contrary, the diameter of powder size for $150-180$ and $200-250$ counts are smaller than the coating film thickness. From this point, it is considered that the number of particles on the surface was decreased with increasing the number of
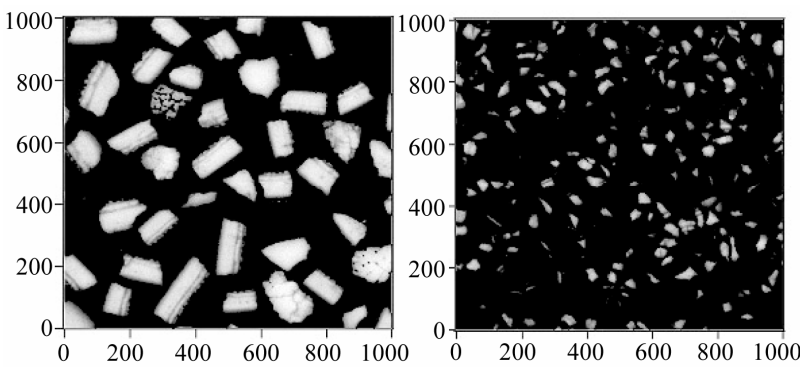

Figure 8. Schematic illustration of pictures for 80-100 and 200 - 250 count.

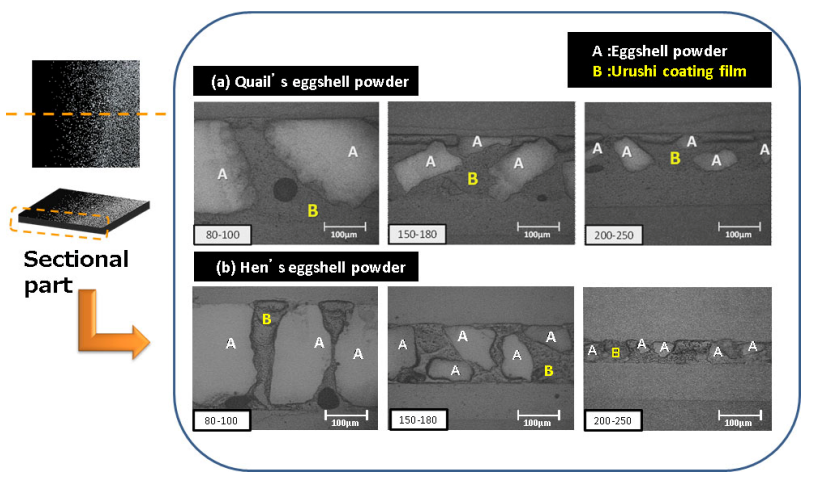

Figure 9. Sectional part and cross-sectional observation pictures; (a) Quail's eggshell powder; (b) Hen's eggshell powder. 
mesh counts filter, i.e. the number of deadhead particles into the coating film was increased. Therefore, it becomes increasingly likely to lose the small particles located near surface and to decrease the area of particles by polishing. In addition, it was indicated that the occupancy of the eggshell powder on the surface depends on the particle size and the increase of the number of particles is not necessarily lead to the increase of the occupancy for a reason of hollowing between particles.

Excluding 80 - 100 count, the occupancy of hen's egg powder was lower than quail's egg in mono-count. In the cross-sectional pictures, the area of hen's egg powder is less than half of quail's one. This result may be from the hen's eggshell powder characteristics. Because the hen's eggshell powder is more fragile than quail's one, this powder is broken during spreading, and then results in many very small powder on the surface. Because these very small powders enter between particles and these are lost during polishing, it is impossible to polish it not to lose powder. Therefore, powder was lost by excessive polishing. Schematic illustration of $200-250$ count before and after polishing is shown in Figure 10.

\subsection{RGB Value and Value, Full Width Half Maximum}

Generally, Urushi craftspeople point out the difference of the white color degree in hen's and quail's egg powder in the viewpoint of art and feeling. Although both powders are used for expressing the white color; the size and dispersion of eggshell powders on the surface gives them the different impression in the facons of products. Therefore, we tried to evaluate the color difference from the picture data. Figure 11 shows the results of RGB values of 80 - 100 count for the pictures of Quail's and Hen's eggshell substrate. The brightness $\mathrm{Y}$ value is calculated by the following equation,

$$
\mathrm{Y}=1.0000 \mathrm{R}+4.5907 \mathrm{G}+0.0601 \mathrm{~B} \text { [18] }
$$

where R, G, and B values are given by each color point in Figure 11. The Y value is shown in Table 2.

It was found that the brightness of quail's eggshell powder indicated slightly higher value than that of hen's one. The R, G, and B value of hen's eggshell powder shows almost same value in contrast to that of quail's eggshell. On the other hand, R and G value of quail's

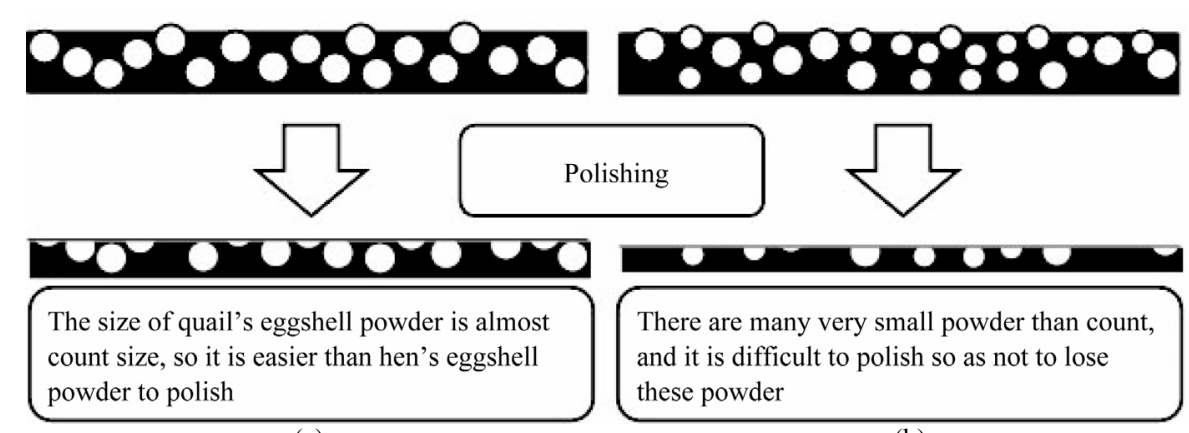

(a)

(b)

Figure 10. Schematic illustration of 200 - 250 count before and after polishing; (a) Quail’s eggshell powder; (b) Hen's eggshell powder.
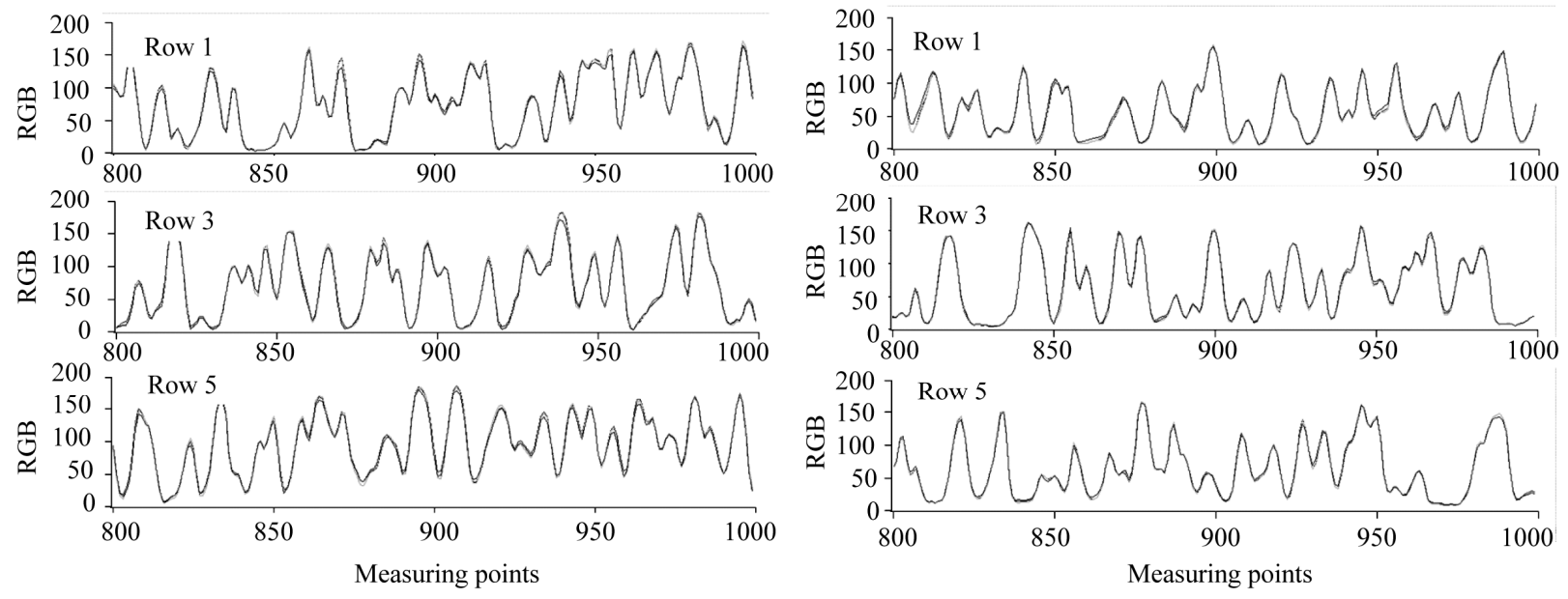

(b)

Figure 11. RGB value and the value of row 1 and 3, 5; (a) Quail's eggshell powder, (b) Hen's eggshell powder. 
Table 2. Value of both eggshell powders which were calculated by RGB value; (a) Quail's eggshell powder; (b) Hen's eggshell powder.

(a)

\begin{tabular}{cccc}
\hline Quail's eggshell & R & G & B \\
\hline AVE & 82.03 & 81.53 & 80.24 \\
SD & 48.62 & 49.53 & 47.51 \\
Max & 186.44 & 185.06 & 181.67 \\
\hline
\end{tabular}

(b)

\begin{tabular}{cccc}
\hline Hen's eggshell & R & G & B \\
\hline AVE & 60.34 & 60.14 & 61.43 \\
SD & 42.25 & 42.74 & 41.65 \\
Max & 165.75 & 166.86 & 165.50 \\
\hline
\end{tabular}

eggshell powder are slightly higher than the B value. It could be due to the inside of quail's eggshell turn brownish slightly, though the inside and the outside of hen's eggshell are white. The outside pattern of quail's eggshell is almost lost during polishing it, but this is not also lost completely. Thereby, the outside pattern can influence the RGB value. The whiteness of both eggshells was decreased with increasing the number of mesh count filter. However, it is considered that the whiteness depends on the factor excluding the occupancy, because the whiteness of material doesn't change. Then, the full width half maximum (FWHM) between the particles was measured from the waves of RGB values in Figure 11.

FWHM which was measured by 10 waves per each count is shown in Figure 12. FWHM and the peak value show the particle width and the maximum value of each peak in Figure 12. The maximum values of both eggshell powders were decreased with decreasing the particle size. According to statistical test of the correlation coefficient $r$, it is significant in significance level 0.01 , if the correlation coefficient is more than 0.33 when sample number is 60. Both correlation coefficients were 0.77 . Consequently, it was found that the whiteness of both eggshell powders depends on the particle size.

\section{Conclusion}

In this research, we demonstrate the relationship between the different kinds of eggshell, i.e. hen's and quail's eggshell characteristics and the powder size on appearance of eggshell Maki-e. The effects are discussed on the basis of the results of particle analysis, circularity, and occupancy on the surface of the eggshell Maki-e substrate. As results, the decrease of circularity was caused from the reason that the particle got out of shape because a part of powder was lost by polishing. Both powders' average area per one particle was decreased with increasing the

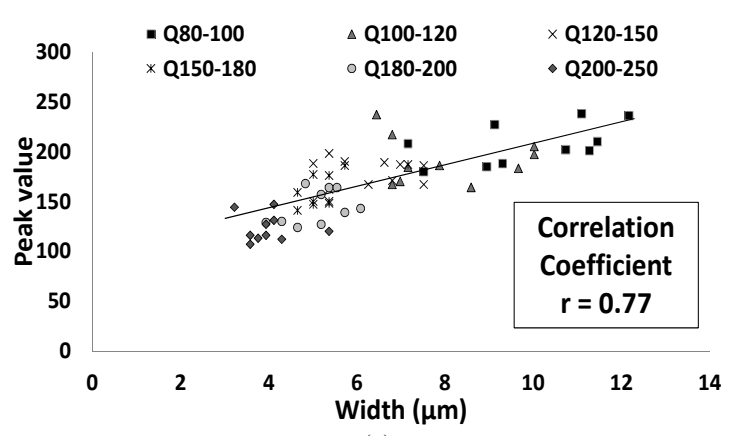

(a)

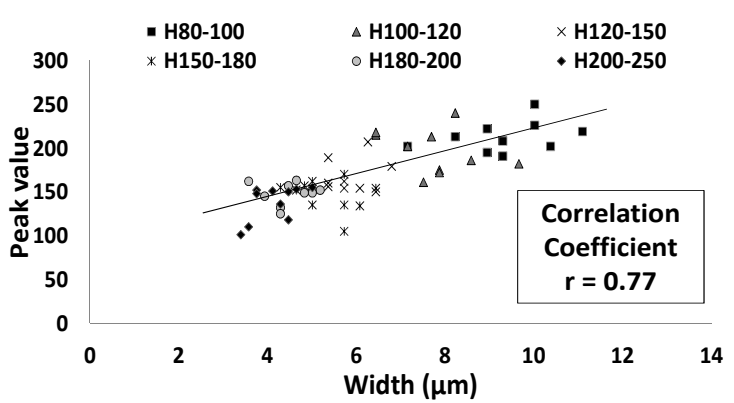

(b)

Figure 12. Relationship between the FWHM and the peak value; (a) Quail's eggshell powder; (b) Hen's eggshell powder.

number of mesh counts filter, however, the hen's egg shell powder didn't show the constant tendency in spite of the decrease ratio of quail's egg which is proportional to the particle size. It was found that the number of particle was increased with increasing the number of mesh counts filter, whereas the occupancy was decreased with decreasing the particles size in both mono- and di-counts. In addition, it was found that the occupancy depends on not particle number but a particle size. The value of quail's eggshell powder is slightly higher than that of hen's one, and R, G, and B value of the hen's eggshell powder shows almost same value, whereas $R$ and $G$ values of the quail's eggshell powder are a bit higher than B value. Consequently, it was indicated that the whiteness of both eggshell powders depend on the particle size as can be seen in the relationship between the FWHM and the maximum values. In the near future, this knowledge could be expected to contribute to the succession of the technique of eggshell Maki-e.

\section{REFERENCES}

[1] A. E. Elmahdy, P. D. Ruiz, R. D. Wildman, M. Huntley and S. Rivers, "Stress Measurement in East Asian Lacquer Thin Films Owing to Changes in Relative Humidity Using Phase-Shifting Interferometry," Mathematical, Physical \& Engineering Science, Vol. 467, No. 2129, 2010, pp. 1329-1347.

[2] T. Honda, Lu, R. Sakai, R. Ishimura and T. Miyakoshi, 
"Characterization and Comparison of Asian Lacquer Saps," Progress in Organic Coatings, Vol. 61, No. 1, 2008, pp. 68-75. doi:10.1016/j.porgcoat.2007.09.003

[3] Y.-Y. Wan, D. Yu-Min, F.-X. Yang, Y. Xu, R.-Z. Chen and J. F. Kennedy, "Purification and Characterization of Hydrosoluble Components from the Sap of Chinese Lacquer Tree Rhus Vernicifera," International Journal of Biological Macromolecules, Vol. 38, No. 30, 2006, pp. 232-240. doi:10.1016/j.ijbiomac.2006.02.019

[4] R. Lu, S. Hairigaya, T. Ishimura, K. Nagase and T. Miyakoshi, "Development of a Fast Drying Lacquer Based on Raw Lacquer Sap," Progress in Organic Coatings, Vol. 51, No. 3, 2004, pp. 238-243.

doi:10.1016/j.porgcoat.2004.08.006

[5] B. H. Lee and H. J. Kim, "Curing Behaviors of Korean Dendropanax Lacquer Determined by Chemical and Physiccal Measures," Journal of Applied Polymer Science, Vol. 92, No. 1, 2004, pp. 625-630. doi:10.1002/app.20094

[6] O. Vogl, "Oriental Lacquer, Poison Ivy, and Drying Oils," Journal of Polymer Science Part A: Polymer Chemistry, Vol. 38, No. 24, 2000, pp. 4327-4335. doi:10.1002/1099-0518(20001215)38:24<4327::AID-PO $\underline{\mathrm{LA} 10>3.0 . \mathrm{CO} ; 2-3}$

[7] E Agostinelli, L Cervoni, A Giartosio and L Morpurgo, "Stability of Japanese-Lacquer-Tree (Rhus Vernicifera) Laccase to Thermal and Chemical Denaturation: Comparison with Ascorbate Oxidase," Biochemical Journal, Vol. 306, No. 3, 1995, pp. 697-702.

[8] J. Bartus, W. J. Simonsick Jr. and O. Vogl, "Oriental Lacquers IX. Polymerizable Ultraviolet Stabilizers for Oriental Lacquers," Polymer Journal, Vol. 27, No. 7, 1995, pp. 703-711. doi:10.1295/polymj.27.703

[9] S. Wei, V. Pintus, V. Pitthard, M. Schreiner and G. Song, "Analytical Characterization of Lacquer Objects Excavated from a Chu Tomb in China," Journal of Archaeo- logical Science, Vol. 38, No. 10, 2011, pp. 2667-2674.

[10] K. Nakagoshi and K. Yoshizumi, "Degradation of Japanese Lacquer under Wavelength Sensitivity of Light Radiation," Materials Sciences and Applications, Vol. 2, No. 10, 2011, pp. 1507-1515.

[11] J. C. Frade, M. I. Ribeiro, J. Graça and J. Rodrigues, “Applying Pyrolysis-Gas Chromatography/Mass Spectrometry to the Identification of Oriental Lacquers: Study of Two Lacquered Shields," Analytical and Bioanalytical Chemistry, Vol. 395, No. 7, 2009, pp. 2167-2174. doi:10.1007/s00216-009-3043-y

[12] C. McSharry, R. Faulkner, S. Rivers, M. Shaffer and T. Welton, "The Chemistry of East Asian Lacquer: A Review of the Scientific Literature," Studies in Conservation, Vol. 8, 2007, pp. 29-40.

[13] G. W. Carriveau, "Technical Examination of Oriental Lacquer," American Chemical Society, Vol. 205, 1984, pp. 395-402.

[14] S. Matsushima, "Viewing Asian Culture through Its Lacquer Crafts: Myanmar Lacquer Culture I," Bulletin of Utsunomiya University, No. 59, 2009, pp. 63-75.

[15] M. Bincsik, "European Collectors and Japanese Merchants of Lacquer in 'Old Japan' Collecting Japanese Lacquer Art in the Meiji Period (1868-1912)," Journal of the History of Collections, Vol. 20, No. 2, 2008, pp. 217 236.

[16] K. Shuppan (Eds.), "Shitsugei Giten," Kougei Shuppan, 2004, p. 342.

[17] The National Museum of Modern Art Tokyo, Ed., "Kindai Nihon-No Shitsugei," Tankosha Publishing, 1981, p. 293.

[18] A. Tremeau, "Color Classification in a Multidimensional Color Space," IEEE International Symposium on Signal Processing and Information Technology, Giza, 15-18 December 2007, pp. 819-824. 